\title{
Distinct quasi-biweekly features of the subtropical East Asian monsoon during early and late summers
}

\author{
Jing Yang • Qing Bao • Bin Wang • Dao-Yi Gong • \\ Haozhe He $\cdot$ Miao-Ni Gao
}

Received: 2 November 2012/ Accepted: 6 March 2013/Published online: 22 March 2013

(c) The Author(s) 2013. This article is published with open access at Springerlink.com

\begin{abstract}
Using Global Precipitation Climatology Project daily rainfall and ERA interim reanalysis data, we investigate the distinct characteristic of quasi-biweekly variation (QBV: 12-20 days) over East Asia (EA) during early (June 10-July 20) and late (July 21-August 31) summer. The QBV maximum variance is found over the core region of EA $\left(30^{\circ}-40^{\circ} \mathrm{N}, 110^{\circ}-130^{\circ} \mathrm{E}\right)$, which includes eastern China (lower reaches of the Yellow, Huaihe, and Yangtze rivers) and the Korean Peninsula. At both its peak wet and dry phases, QBV over the core region has a baroclinic structure, but with different spatial distributions, different lower-level prevalent wind anomalies, and different upperlevel major circulation anomalies in the two subseasons. Meanwhile, the two subseasons have different propagating tracks prior to reaching the peak phase, and different precursors associated with the local genesis of QBV. Furthermore, during the transition from the peak dry to peak wet phase of QBV, the major monsoon circulations have different behaviors that tropical monsoon trough extends eastward in early summer but retreats westward in late summer and the South Asia high (SAH) and western North Pacific (WNP) subtropical high move toward (away from)
\end{abstract}

J. Yang $(\bowtie) \cdot$ D.-Y. Gong $\cdot$ H. He · M.-N. Gao

State Key Laboratory of Earth Surface Processes and Resource Ecology (ESPRE),

Beijing Normal University, Beijing 100875, China

e-mail: yangjing@bnu.edu.cn

Q. Bao

State Key Laboratory of Numerical Modeling for Atmospheric Sciences and Geophysical Fluid Dynamics (LASG), IAP/CAS, Beijing, China

B. Wang

Department of Meteorology, and International Pacific Research Center, University of Hawaii at Manoa, Honolulu, HI, USA each other in early (late) summer. The abrupt change of mean state in mid to late July, which includes the northward migration of westerly jet, SAH and WNP, and the weakening and broken of westerly jet, is considered the root cause of the change in behavior of QBV. Finally, we indicate that the tropical monsoon trough and midlatitude westerly jet are possible sources of QBV over subtropical EA in both subseasons and provide useful guidance for 2-3 week predictions over EA.

Keyword Quasi-biweekly · East Asian summer monsoon

\section{Introduction}

Quasi-biweekly variation (QBV) is a salient high-frequency component of intraseasonal variability (e.g., Kikuchi and Wang 2009), which has periodicities that fall outside the category of the conventional Madden-Julian oscillation (MJO) (Madden and Julian 1971, 1972) that has a 40-50 or 30-60 day energy peak (Madden and Julian 1994). QBV often triggers and enhances severe regional flooding (Chan et al. 2002; Yang and Li 2003; Mao and Wu 2006; Sun and Ding 2008); consequently, knowledge of its temporal evolution and spatial structures is critical for improving regional intraseasonal weather and climate prediction.

The behavior of QBV modes tends to be region-dependent. For example, over the Indian monsoon region, QBV originates in the equatorial western Pacific and propagates westward to the Bay of Bengal (e.g., Krishnamurti and Bhalme 1976; Annamalai and Slingo 2001; Chatterjee and Goswami 2004). Over the western Pacific, the QBV mode is characterized by a northwestward propagation from the equator to the western North Pacific (WNP) (e.g., Chen and Chen 1995; Yang et al. 2008; Chen and Sui 2010). A recent 
study documented the major activity centers of QBV and their life cycles over the global tropics observed in 27 years of outgoing longwave radiation (OLR) data (Kikuchi and Wang 2009), and found eight regional QBV modes with different propagation tracks between $10^{\circ}$ and $30^{\circ}$ latitude in both hemispheres (summarized in their Fig. 13).

Over subtropical East Asia (EA), QBV has been found to be an important mode of the intraseasonal variation of precipitation and convection during summer (Chen et al. 2000; Ko and Hsu 2006; Mao and Wu 2006; Zhan et al. 2008; Fujinami and Yasunari 2009; Yang et al. 2010). Previous studies have attempted to investigate the features of the QBV over subtropical EA, including structure, propagation and sources. With respect to its structure, Mao and Wu (2006) found that the QBV extreme dry (wet phase) over Yangtze River during 1991 summer features an anomalous low-level cyclone (anticyclone) over the northern South China Sea (SCS) and the Philippine Sea, and an upper-level anomalous cyclone (anticyclone) over eastern China and an upper-level anomalous anticyclone/cyclone over the northern Tibetan Plateau (TP); Ko and Hsu (2006) found that the vertical structure of QBV over western North Pacific during JulyAugust exhibits a barotropical structure below $500 \mathrm{hPa}$ that gradually tilts northwestward in upper levels near Taiwan and southern Japan; Fujinami and Yasunari (2009) exhibited a baroclinic structure of QBV extreme phases over Yangtze and Huaihe River Basins during Meiyu season. In terms of its propagation, some studies found that the QBV signal over subtropical EA is associated with the tropical disturbance, which either propagates northwestward from western Pacific (Ko and Hsu 2006; Zhan et al. 2008) or propagates westward from tropical central Pacific (Mao and Wu 2006); some studies proposed that the QBV signal over subtropical EA comes from eastward or southward propagating transient wave in mid-latitude (e.g., Fujinami and Yasunari 2009); and some studies found the QBV events over subtropical EA are associated with both eastward propagation from midlatitude and northwestward propagation from tropical western Pacific (Wu et al. 1994; Yang et al., 2010). Thus, the sources of the biweekly oscillation over subtropical EA are considered to be different regions, e.g., tropical western Pacific (Wu et al. 1994; Ko and Hsu 2006; Zhan et al. 2008; Yang et al. 2010), tropical central Pacific (Mao and $\mathrm{Wu} 2006$ ), mid-latitude westerly jet (Liu and $\mathrm{Li}$ 1986; Fujinami and Yasunari 2009; Yang et al. 2010) and Lake Baikal (Wu et al. 1994).

The above review indicates that the features of QBV over subtropical EA have not been documented in as comprehensive and unified a manner as MJO. The inconsistency in the QBV behavior is partly associated with the differences among datasets, historical records, selected cases, and selected core regions. In addition, the abrupt climatological seasonal March in mid to late July during the Asian summer monsoon (e.g., Wu and Wang 2001; LinHo and Wang 2002; Ding 2004) could bring subseasonal modulation to QBV behavior. Many previous studies have confirmed the effect of this subseasonal change on the characteristics of intraseasonal variations (e.g., Fukutomi and Yasunari 2002; Pan et al. 2008; Fujinami and Yasunari 2009). Does the subseasonal March around mid-July influence the QBV behavior over EA? If yes, how and why are the QBV behaviors different between the two subseasons? The above questions have not been clarified yet and worthwhile to investigate in this study.

Furthermore, some of the above studies applied gaugeobserved station rainfall, which is not available over the ocean (Mao and Wu 2006; Yang et al. 2010). The other studies used OLR to investigate the evolution of rainfall associated with QBV over subtropical EA (e.g., Fujinami and Yasunari 2009), which can represent well the convective rainfall but not the stratiform precipitation that is an important type of precipitation over subtropical EA (e.g., Fu and Liu 2003). To reveal reliable signals from mid-high latitudes and cover features over the ocean, this study applies daily rainfall data from the Global Precipitation Climatology Project (GPCP) to depict the day-to-day rainfall variation over subtropical EA. This dataset provides rainfall over both land and ocean.

Therefore, using more reliable datasets, this study attempts to investigate the features of the QBVs over subtropical EA respectively in early and late summers, focusing on their similarity and difference between the two subseasons. The following questions are to be answered respectively for the early and late summers: What are the structure and evolution of the QBV over subtropical EA? How are the local QBV generated? How different are the behaviors of the major circulation systems associated with the QBV over subtropical EA? What are the sources of the QBV signals over subtropical EA? How do the abrupt change of seasonal mean state, which occurs around midto-late July, modulate the QBV behavior?

The remainder of this article is organized as follows. Section 2 briefly introduces the datasets and methodology, and Sect. 3 explains the selection of the core QBV region and the significant QBV cases over EA. The structure, evolution, and local genesis of QBV over the core region in early and late summer are introduced in Sect. 4. The associated variations of the tropical monsoon trough, South Asia high, and WNP subtropical high in two subseasons are discussed in Sect. 5. Finally, Sect. 6 summarizes the commonalities and differences between QBV behaviors in the two subseasons, and discusses reasons for differences between the two seasons and the possible sources of QBV over EA. 


\section{Datasets and methodology}

To cover both land and ocean, this study uses daily rainfall data from the Global Precipitation Climatology Project (GPCP), which has a spatial resolution of $1^{\circ} \times 1^{\circ}$, and combines both rain gauge and satellite observations (Huffman et al. 2001). ERA-Interim from the European Centre for Medium-Range Weather Forecasts (Simmons et al. 2007), which is a newly released reanalysis dataset at finer resolution $\left(1.5^{\circ} \times 1.5^{\circ}\right)$ than ERA-40 (http://dataportal.ecmwf.int/data/d/interim_daily/), is used here to depict daily circulation changes in more detail. The period selected from both datasets covers 11 years, from 1997 to 2007.

The intraseasonal variation (ISV) component was obtained from the "raw" daily precipitation time series by first removing climatology, and then removing synoptic fluctuations by taking a 5-day running mean (for details of the methodology, see Yang et al. 2010). The QBV component is then extracted from the ISV component by using a 12-20 day time filtering based on Fourier harmonic analysis. Therefore, QBV corresponds to 12-20 day variation.

To identify QBV periodicity statistically, we first apply the fast Fourier transform (FFT) with a tapered window (Bingham et al. 1967), which is one of the most common methods of spectral analysis, to the time series of ISV over a given location during a given season (June-August) in each year. We then calculate the average of individual power spectra for the 11 summer seasons (1997-2007). Statistical significance of power spectra was tested according to the method of Gilman et al. (1963) based on the power spectrum of mean red noise.

Phase composite analysis (for details, see Sect. 3.2) is applied to specified variables to identify the spatial structure and temporal evolution of QBV (for details, see Sect. 3 ), and a lead-lag correlation analysis is applied to the 12-20 day filtered rainfall averaged over the core region at the peak wet phase. Given that the results of the composite analysis and correlation analysis are similar, the following sections only show the results of the phase composite analysis. The statistical significance of composite fields is estimated by using Student's $t$ test.

\section{Selection of core region and significant cases of QBV over EA}

\subsection{Core region of QBV over East Asia during June-August}

Based on 11 years of GPCP data, Fig. 1 illustrates the June-July-August (JJA) mean precipitation (Fig. 1a) and the JJA climatological mean QBV variance of precipitation (Fig. 1b). The maximum variance of QBV occurs over the domain $\left(30^{\circ}-40^{\circ} \mathrm{N}, 110^{\circ}-130^{\circ} \mathrm{E}\right)$ (Fig. 1b), which is regarded as the core region of QBV over East Asia in this study. This core region covers the lower reaches of the Yellow, Huaihe, and Yangtze rivers, and the Korean Peninsula. Figure 1c presents an 11-summer-averaged power spectrum of the ISV component of area-averaged rainfall over this region for the period from 1997 to 2007. Based on the $99 \%$ prior confidence level, the 12-20-day band can be well identified over the core region during boreal summer, demonstrating that QBV is one of the most important ISV components over the core region. Figure $1 \mathrm{~d}$ shows the seasonal variation of 11-summer averaged 12-20 day variance, which indicates that QBV over the core region is most active during JJA, with a maximum in July. Therefore, the following study will focus on JJA, which is also typically a rainy season over subtropical EA. The areaaveraged fractional variance (percentage variance) of QBV against the total ISV over the core region is $36 \%$ during the JJA season, which further indicates that QBV is an important ISV mode over EA in summer.

\subsection{Selecting the significant cases of QBV over the core region}

To document the structure and evolution of QBV over EA, first we need to choose significant cases of QBV over the core region during the whole JJA season in the years 1997-2007. The area-averaged daily time series of total (unfiltered) rainfall and 12-20 day filtered rainfall are examined over the core region year by year. Three major criteria were used to select the significant QBV cycles: (1) both the maximum amplitude in the wet phase and one of the minimum amplitudes in the dry phase exceed 0.8 standard deviations of the time series of the area-averaged band-filtered rainfall; (2) one wet peak and two dry peaks in the selected QBV event from the time series of the bandfiltered rainfall can be well identified in the time series of total rainfall, and the total rainfall amount at two dry peaks should be less than $5 \mathrm{~mm} /$ day; and (3) each selected QBV case can include several synoptic processes (because a high-frequency synoptic disturbance (3-8 days) is prevalent over the core region during summer), but the unfiltered rainfall amount at the synoptic dry phase is more than that at two dry peaks of QBV, which confirms that QBV is a dominant perturbation in this selected event. According to these three criteria, 21 significant QBV cycles are selected from the 11 summers (Fig. 2a).

Climatologically, circulation fields change abruptly around mid to late July (LinHo and Wang 2002; Ding 2004). Hence, we divide the whole summer season (JJA) into two periods: early summer (June10th-July 20th) and 


\section{(a) Climatology}

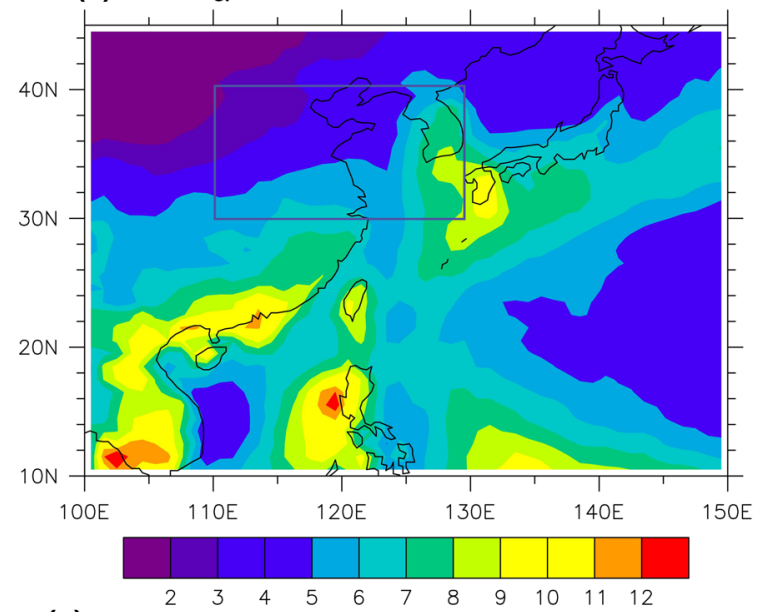

(c) Power spectral of reference domain

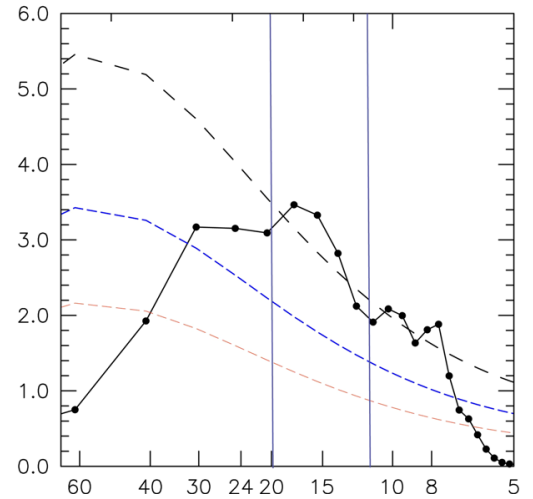

Fig. 1 a 11-year climatological total rainfall during JJA (mm/day); b 11-year climatological 12-20-day variance of rainfall during JJA $\left(\mathrm{mm}^{2} / \mathrm{day}^{2}\right)$; c 11-summer (JJA) mean power spectra of the rainfall ISV component over the LYRB region, with Markov red noise spectrum (red dashed line), a priori $99 \%$ confidence bound (blue

late summer (after July 20th-August 31). Among the 21 QBV cases, 9 occur in early summer and 12 in late summer (the third case in 2002 belongs to late summer). Why we start the analysis from mid-June has three reasons. First, we found most selected strong cases of QBV occur after midJune; second, the climatological rainy season over the core region starts Meiyu onset around mid-June (e.g., Ding 1992); third, the wavelet power analysis shows that the biweekly signal is most significant after mid-June (Figure ignored).

To perform a composite analysis of the significant QBV cases, we separate each cycle of the selected QBV events into eight phases (Fig. 2b). Phase 1 is the minimum (peak dry phase), and phase 5 is the maximum (peak wet phase). Phases 3 and 7 are the transitions from dry to wet phase, and from wet to dry phase, respectively. Phases $2,4,6$, and 8 occur at the times when the cycle reaches half of its maximum or minimum value. Thus, the structure and propagation of QBV are examined based on its life cycle,

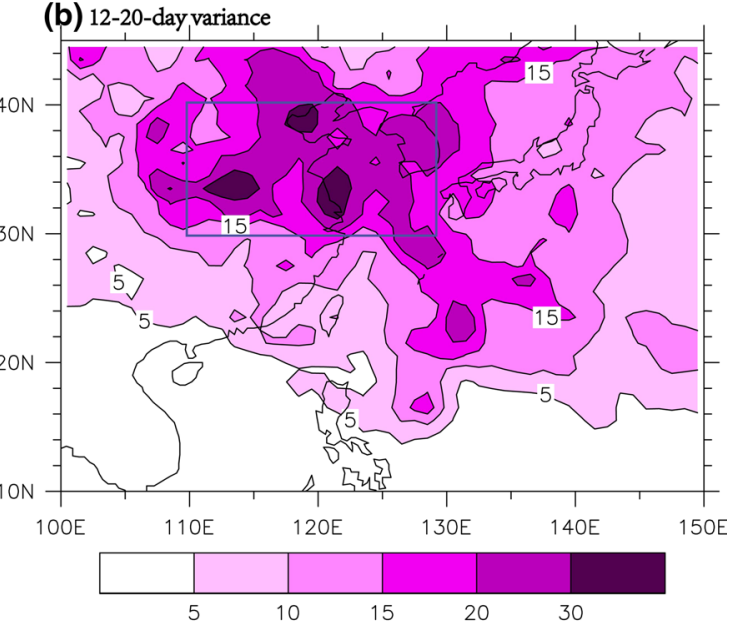

(d) Seasonal change of 12-20-day variance

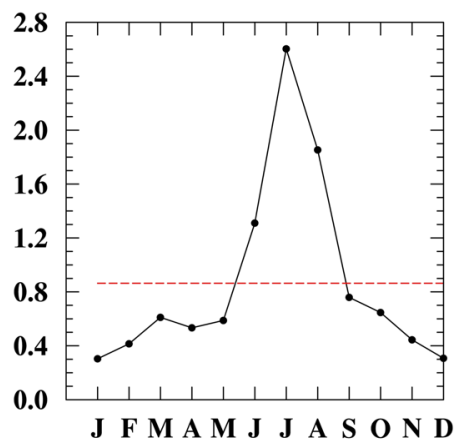

dashed line), and a posterior $99 \%$ confidence level (black dashed line), the $\mathrm{x}$ abscissa has been rescaled into the natural logarithm of the frequency, and the corresponding y abscissa times frequency; d 11-year mean seasonal variation of 12-20-day standard deviation ( $\mathrm{mm} /$ day) from January to December

which is determined using a phase compositing technique (e.g., Fujinami and Yasunari 2004; Mao and Chan 2005).

\section{Characteristics of QBV in early and late summer}

To investigate the structure, propagation, and genesis characteristics related to QBV over the core region, we applied the 8-phase compositing technique to the 12-20 day filtered fields from the selected significant cases, including precipitation, lower- and upper-tropospheric circulation, vorticity, divergence, specific humidity, and temperature.

\subsection{Structure and propagation of QBV in early summer}

During early summer, a lower-tropospheric cyclonic anomaly (CA) (Fig. 3) and an upper-tropospheric anticyclonic anomaly (AA) (Fig. 4) appear above the core region of EA, when the maximum rainfall anomaly occurs there 
(a) Time series of each year
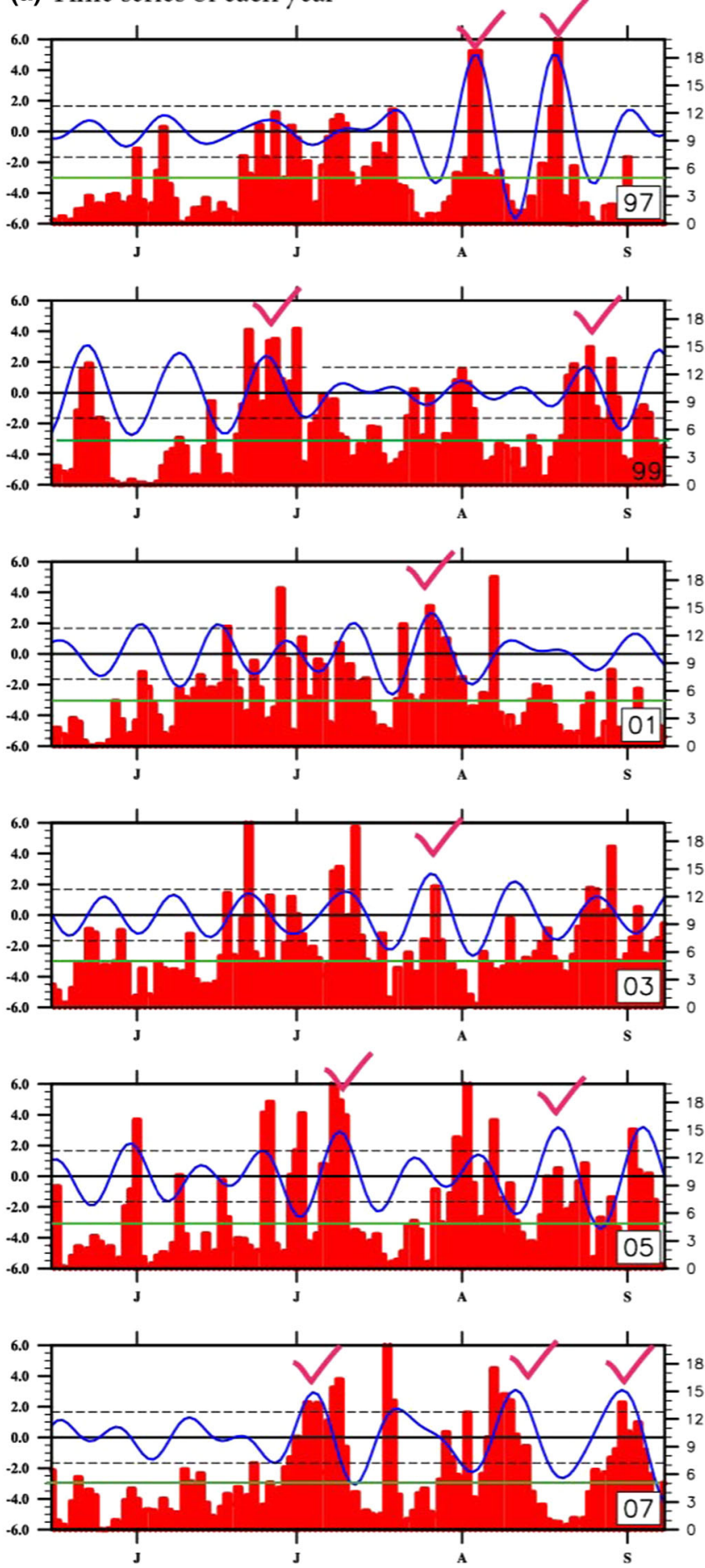

Fig. 2 a Time series of 12-20-day filtered rainfall (blue solid line) with values in the right y axis and unfiltered rainfall (red bar) with values in the left $y$ axis averaged over the core region during each summer of 11 year; the red ticks denotes 21 significant cases of QBV;

(phase 5). This indicates that QBV over EA has a baroclinic structure at its peak phase in early summer, similar to the MJO. At peak wet phase, both the upper-level AA and


(b) phase

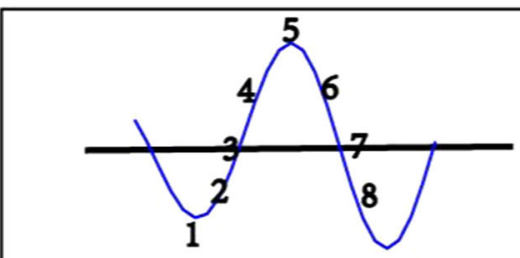

the dashed line represents one standard deviation; and the green solid line represents $5 \mathrm{~mm} /$ day of unfiltered rainfall. The unit is $\mathrm{mm} /$ day; b an example of eight phases in one life cycle used in the phase composing technique

lower-level CA have an east-west elongate shape, and the core region is dominated by an anomalous westerly. A wave train pattern along the Asian westerly jet appears in 
the upper troposphere at peak wet phase, consisting of an AA over the Aral Sea, a CA over northwestern Tibetan Plateau (TP), and an AA over the core region. In contrast, a north-south dipole mode appears in the lower troposphere along the coast of eastern China, with a CA over the core region and an AA over the northern South China Sea (SCS) and Philippine Sea (PS). A mirror image of the phase-5 features can be seen clearly at phase 1 , when the minimum rainfall anomaly occurs over the core region.

To understand where the maximum wet phase of QBV with the baroclinic structure originates, the evolution of
QBV from peak dry phase (phase 1) to peak wet phase (phase 5) is examined in both the lower and upper troposphere. First, we investigate where the lower-tropospheric CA over the core region originates. In the lower troposphere (Fig. 3), we notice that a CA first starts over the northern SCS-PS in phase 1 (at peak dry phase). From phase 1 to 3 , the CA moves northwestward from the northern SCS-PS, and lands on southeastern China at phase 3. Meanwhile, southwesterly anomalies appear over the coast of southeastern China and the core region at phase 3. At phase 4, an AA appears over the northern PS, which

Biweekly filtered wind 850 \& precipitation in early summer
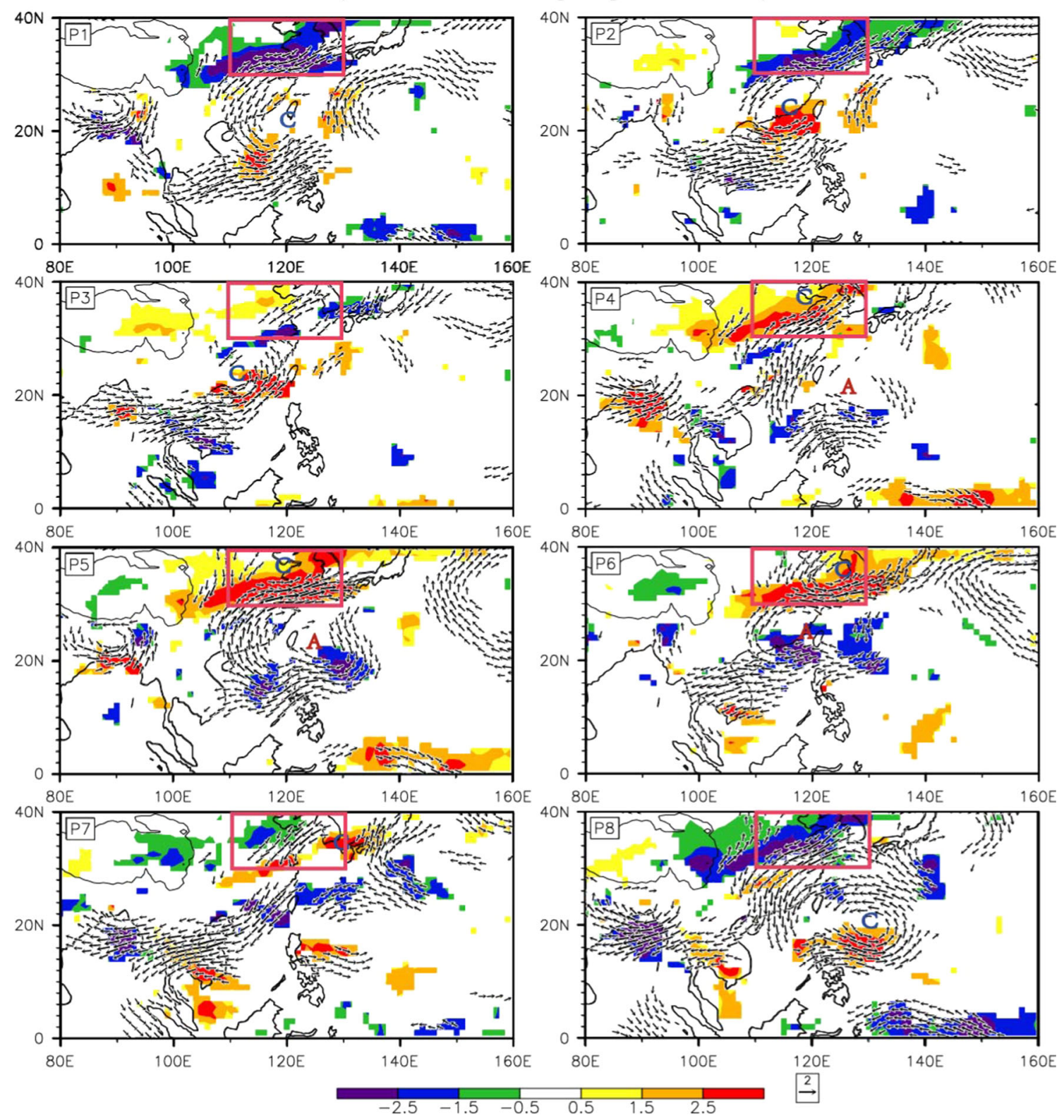

Fig. 3 Temporal evolution of $850 \mathrm{hPa}$ winds (vector $\mathrm{m} / \mathrm{s}$ ) and rainfall (shading $\mathrm{mm} /$ day) in 12-20-day band based on eight phases composite technique in early summer; the green vector represents the zonal/meridional wind above $95 \% t$ test significance level. " $A$ " and " $C$ " respectively donate the centers of anticyclonic anomaly and cyclonic anomaly 
Biweekly filtered wind $200 \mathrm{hPa}$ in early summer
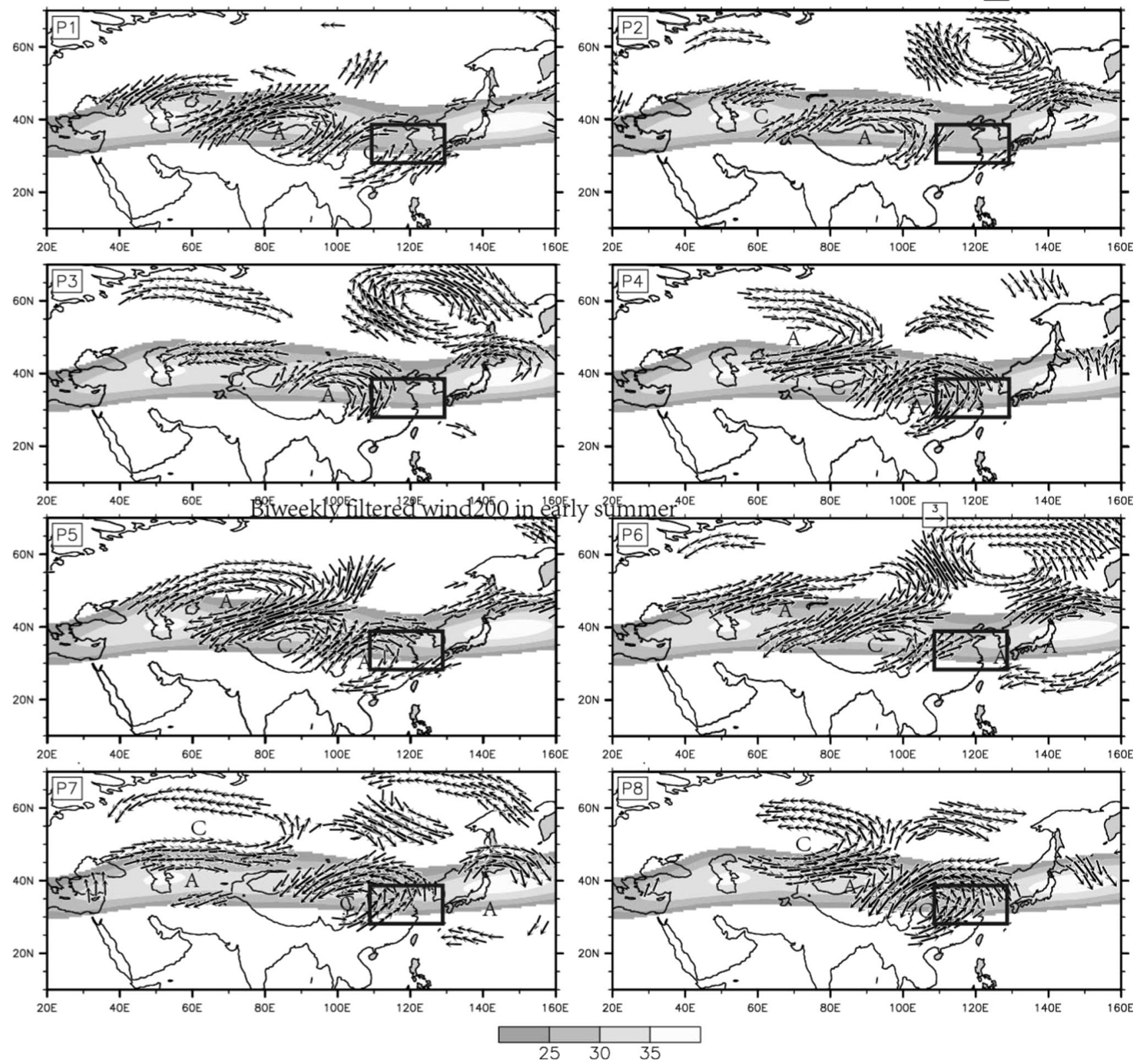

Fig. 4 Temporal evolution of $200 \mathrm{hPa}$ winds (vector $\mathrm{m} / \mathrm{s}$ ) in 12-20day band and total zonal wind (shading $\mathrm{m} / \mathrm{s}$ ) based on eight phases composite technique in early summer; and the wind vector represents

enhances the anomalous southwesterly along eastern China, and a CA can be detected over the core region. At phase 5, the westerly is enhanced south of the core region, and the CA over the core region is well developed, accompanied by the northwestward propagation of the northern PS-SCS AA. In the second half of the life cycle, from phase 5 to 8 , the CA over the core region moves eastward and dissipates to the southwest of Japan. At phases 7 and 8, a new lower-level CA develops over the northern PS (phase 8 can be regarded as the phase that leads phase 1 by one phase), and is ready for the next cycle.

the zonal/meridional wind above $95 \% t$ test significance level. " $A$ " and " $C$ " respectively represent the centers of anticyclonic anomaly and cyclonic anomaly

Briefly, the tropical lower-level CA takes an approximately northwestward recurving path from the northern PS to southeastern China from phase 1 to 3. Simultaneously, the local CA gradually develops from phase 3 to 4 and moves eastward, finally decaying to the southwest of Japan. The intensification of the lower-level anomalous southwesterly over eastern China is the forerunner of the peak-rainfallphase occurrence of QBV over the core region.

The evolution of the associated rainfall anomalies is characterized by two important features: eastward propagation in the subtropics, and northwestward propagation in 
the tropics. In the subtropics, the positive anomaly first appears over eastern TP at phase 2, propagates eastward to the core region at phases 3 and 4 , peaks over the core region at phase 5 , and then moves eastward to southern Korea and Japan at phases 6 and 7. In the tropics, the positive anomaly first appears over the northern SCS-PS at phase 1 , moves northward and northwestward to southeastern China from phase 2 to phase 3, weakens over the coast of southeastern China at phase 4, and then "jumps" to the core region, where it abruptly strengthens.

In the upper troposphere, the associated significant anomalies display a "Silk Road pattern"-like wave train (Fig. 4). The wave train propagates eastward, nearly along the jet stream, starting from the Aral Sea, via northwest of TP and TP, then arrives at the core region, and finally dissipates southeast of Japan. Therefore, the arrival of the upper-level AA over the core region at the peak phase actually belongs to one part of the wave train propagation. From phase 2 to 5, the AA movement is consistent with the above-mentioned eastward movement of the rainfall anomaly in the subtropics.

\subsection{Structure and propagation of QBV in late summer}

In late summer, QBV over subtropical EA is also characterized by the baroclinic structure at peak wet phase, and by the lower-level CA and upper-level AA over the core region (see phase 5 in Figs. 5, 6). However, the upper-level AA is not as strong as that in early summer. Instead, the most significant upper-level circulation feature over the core region is the anomalous southwesterly. In the lower troposphere, instead of the north-south dipole mode in early summer, the lower-level circulation features one CA over the core region and two AAs (one over the southwest of Japan and one over the tropical western Pacific) at peak wet phase. Meanwhile, the lower-level CA over the core region is elongate north-south in late summer rather than the east-west elongation of early summer. Therefore, the evident anomalous southerly dominates coastal eastern China in late summer instead of the anomalous westerly of early summer. The positive rainfall center is located farther northward over the core region, when compared with that in early summer. At peak wet phase, the upper troposphere is characterized by an AA centered over the Caspian Sea and a CA centered over the northeastern corner of TP, which is different from the upper-level northwest-southeast wave train in early summer.

If we want to track back to the formation of the lowerlevel CA over the core region at peak wet phase in late summer, we should go back to phase 7 , which can be regarded as the phase that leads phase 1 by two phases. It is found that a CA starts over the tropical western Pacific at phases 7 and 8, and moves westward via the PS to the SCS from phase 1 to 3 . The local CA over the core region begins to develop at phase 4 and becomes well organized at phase 5. After the peak wet phase, the CA moves eastward and decays over southeastern Japan. The intensification of the lower-level anomalous southerly along the coast of eastern China is the forerunner of the peak-wet-phase occurrence of QBV over the core region. The increased lower-level anomalous southerly is caused by the eastwardpropagating AA, which was previously located over the core region at phase 1 (peak dry phase).

In the upper troposphere, the systematic eastwardpropagating wave train of early summer cannot be clearly seen in late summer. Instead, the anomalous southwesterly becomes most remarkable over the core region at peak wet phase, which belongs to the CA to the northeast of TP. The associated signal can be dated back to phase 2, when a CA appears south of Lake Baikal. From phase 2 to 5, the CA moves southward via the Mongolia Plateau to northeastern TP. After the peak wet phase, the CA continuously moves southward in a clockwise direction, migrates over eastern TP at phase 6, passes south of TP at phase 7 almost along the eastern edge of TP, and finally dissipates south of TP at phase 8 . The relatively weak AA develops over the core region at peak wet phase, and then moves eastward before decaying over the southeast of Japan from phase 5 to 8 .

\subsection{Local evolution over the QBV core region during early and late summer}

As mentioned above, QBV over the core region at the peak phase features the baroclinic structure of circulation anomalies coupled with the positive rainfall anomaly. This leads to the questions of how the local circulation and rainfall anomalies are generated at peak wet phase, and what are the differences between the two subseasons. We make further analyses of the evolutions of the area-averaged thermal and dynamical fields over the core region associated with the biweekly cycle, separately for early and late summer (Fig. 7).

In early summer, the lower-level convergences first appear below $700 \mathrm{hPa}$ at phase 2 and reach the maxima at phase 4 (Fig. 7). The significant positive specific humidity anomalies also first appear in the lower level at phase 3, and then propagate upward and form a deep layer of moist air embedded throughout the troposphere from phase 4 to 6 , with maxima around $750 \mathrm{hPa}$ at phase 4 . The increase of moisture in the lowest layer evidently precedes the peak of rainfall in early summer. A remarkable leading signal can also be seen in vertical motion. That is, the ascending anomalies that occur from the lower level to the mid-upper level can be clearly detected before the peak wet phase. The preceding lower-level convergence, the increased moisture, and the upward motion all favor the formation of 
Biweekly filtered wind850 \& precipitation in late summer



Fig. 5 Same with Fig. 3, except for the late summer

peak wet phase. Accordingly, a warming anomaly that appears in the middle troposphere is caused by condensation heating release due to rising moist air. The cooling anomalies above and under the warming anomaly may arise from adiabatic cooling associated with radiation and the evaporation of raindrops. In summary, the most notable feature in early summer is that the lower-level fluctuations generally lead the peak phase and the upper-level transient perturbation by one or two phases.

Compared with the local evolution of biweekly transient fluctuations in early summer, the phase-leading relationship between the lower- and upper-level fluctuations almost disappears in late summer. In contrast, the divergence firstly appear in the upper-level at phase 2, which leads the convergence of the lower level by two phases in late summer (Fig. 7b). The maxima of the anomalous lower-level convergence are in phase with peak wet phase (Fig. 7b). The increased moisture below $850 \mathrm{hPa}$ and the anomalous ascent can be seen slightly leading peak wet phase, but the leading tendency is not as remarkable as in early summer. Correspondingly, the mid-tropospheric warming occurs after peak wet phase (Fig. 7b) in late summer. The late-summer upper-level divergences and vorticities are found to be stronger and deeper throughout the upper and mid-troposphere than those in early summer. All of the above features indicate that the upper-level 
Biweekly filtered wind $200 \mathrm{hPa}$ in late summer
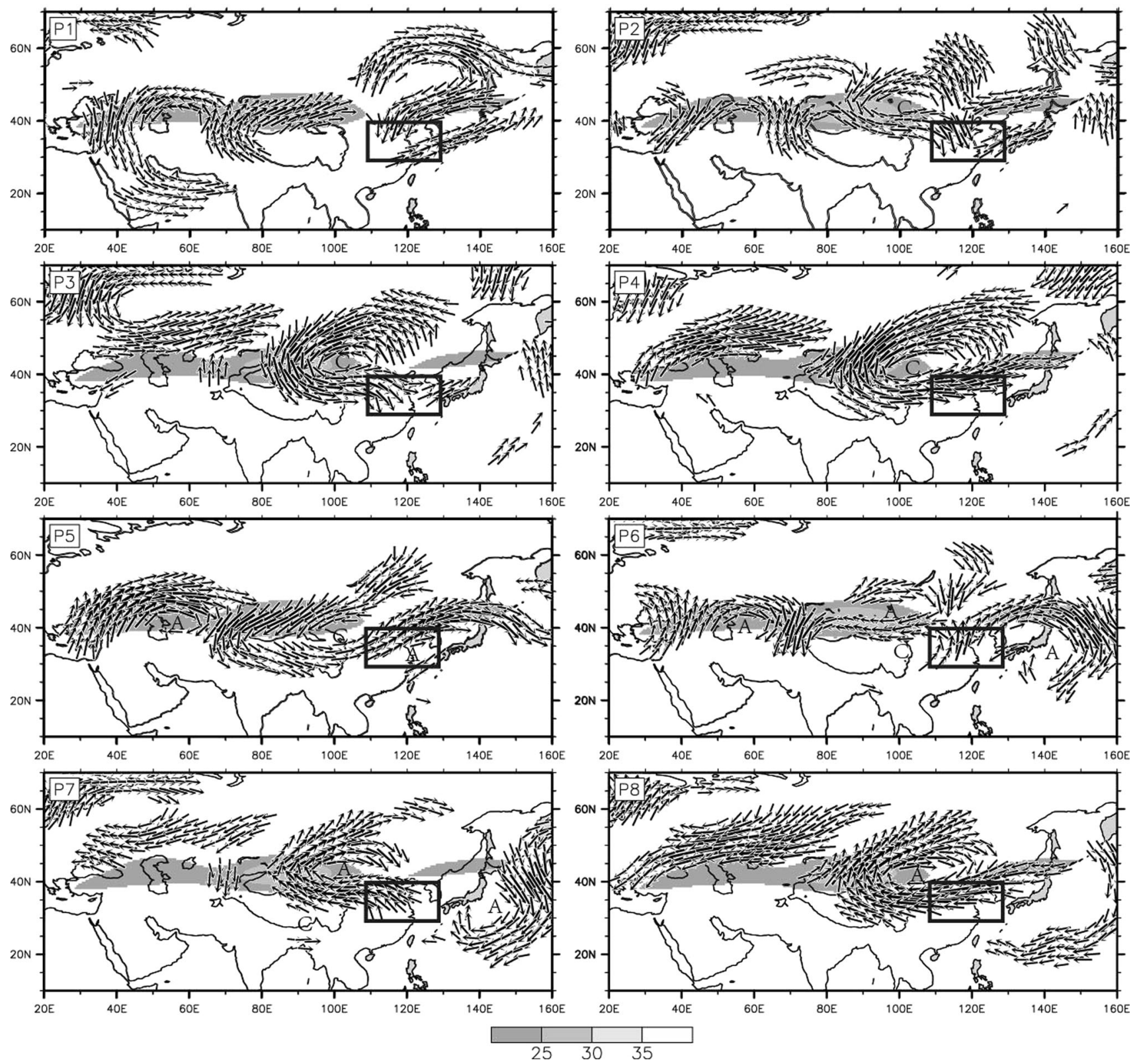

Fig. 6 Same with Fig. 4, except for the late summer

divergence and low-level convergence could be the earlier signal for the occurrence of peak positive rainfall over the core region in late summer.

\section{Variations of large-scale circulation systems associated with QBV over EA}

We have known the behaviors of transient biweekly fields in Sect. 4. But how do the total fields vary accompanied with the biweekly variation? Here, we focus on examining the behaviors of the WNP tropical monsoon trough (hereafter monsoon trough), WNP subtropical high, and South Asia high, which are three important circulation systems of the Asian summer monsoon, in association with QBV, respectively in early and late summer.

The lower-level monsoon trough over the SCS-PS with northwest-southeast tilt is one of the important Asian monsoon components. The southeasterly to its north brings abundant moisture from the SCS and western Pacific to EA. The monsoon trough is also a significant genesis region for tropical cyclones (e.g., Harr and Elsberry 1995). Associated with QBV over the core region, the monsoon trough exhibits a different evolution during early and late 
Fig. 7 Phase (x-axis)-pressure (y-axis: $\mathrm{hPa}$ ) diagrams in the key region of the composite values of the 12-20-day filtered a divergence $\left(1 / \mathrm{s} \times 10^{-6}\right)$;

b specific humidity $\left(\mathrm{kg} \times 10^{-6}\right)$; c temperature $\left({ }^{\circ} \mathrm{C}\right)$, and d vertical velocity $\left(10^{3} \mathrm{~m} / \mathrm{s}\right)$; respectively in early and late summers (a) Early summer

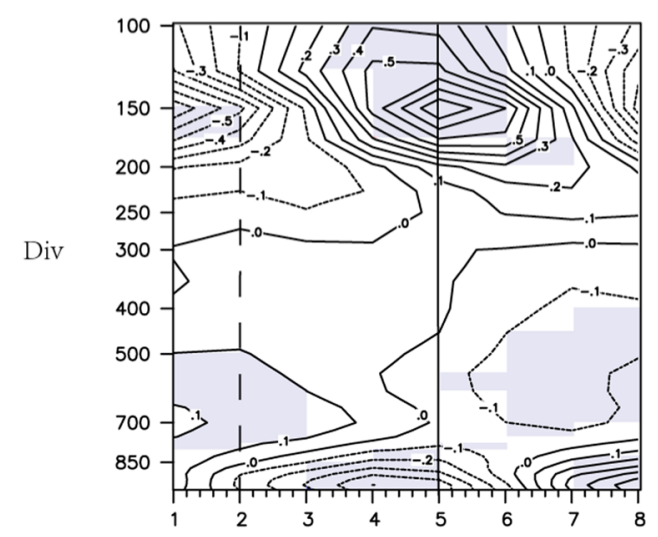

(b) Late summer
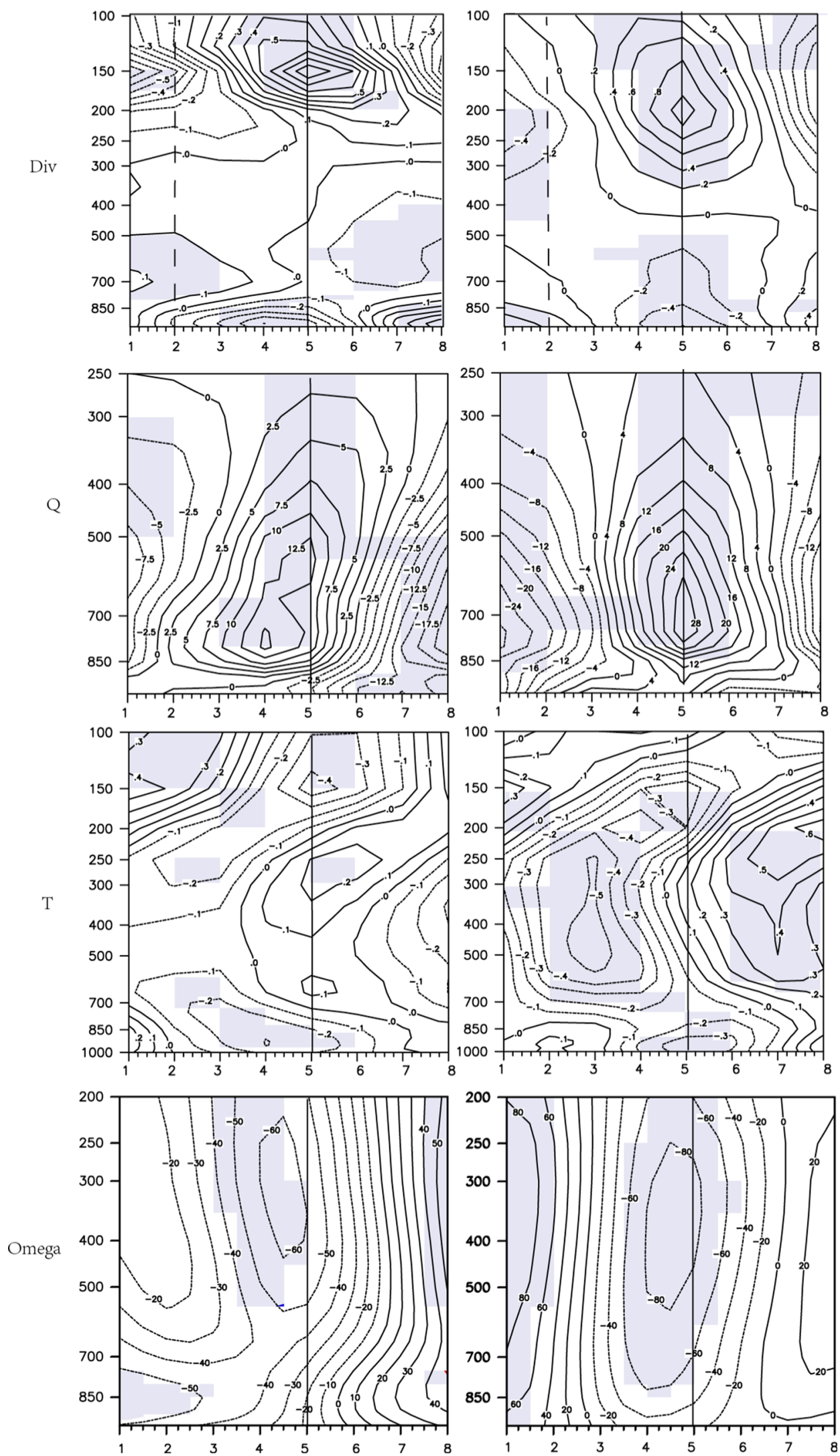
summer (Fig. 8a, b, respectively). During the period from peak dry phase to peak wet phase, the monsoon trough extends eastward in early summer, while it retreats westward in late summer.

The South Asia high and WNP subtropical high are the other two important components related to the EA summer monsoon. Both show an east-west oscillation during the life cycle of QBV in both early and late summer (Figs. 9, 10 ), which has been found by a number of previous findings (Liu and Lin 1991; Zhao et al. 2000; Mao et al. 2010). Meanwhile, associated with the evolution of QBV over EA, the extensions of the South Asia high and WNP subtropical high are in opposite directions. That is, if the South Asia high extends eastward, the WNP subtropical high extends westward, and vice versa. From peak dry phase to peak wet phase, the South Asia high extends eastward while the WNP subtropical high extends westward in early summer; in contrast, the South Asia high retreats westward while the WNP subtropical high retreats eastward in late summer from peak dry to wet phase.

Another focus is the evolution of mid-upper-level flow over EA in the biweekly cycle, which is shown in Fig. 11. In early summer, a blocking high to the east of Lake Baikal experiences a break from peak dry phase to peak wet phase. A trough over northeastern China can be seen in both peak dry and wet phases over EA, but rotates a little in the clockwise direction along the trough axis from peak dry to wet phase. In late summer, the transition from
Fig. 8 Composite $850 \mathrm{hPa}$ total wind fields respectively at phase 1 (extreme dry phase) and phase 5 (extreme wet phase) respectively in a early summer and $\mathbf{b}$ late summer; the red line roughly represents the location of tropical Monsoon trough
Fig. 9 Composite isolines (575 geopotential height $10 \mathrm{~m}$ ) of $500 \mathrm{hPa}$ geopotential height respectively at phase 1 (extreme dry phase) and phase 5 (extreme wet phase) respectively in a early summer and b late summer (a) early summer
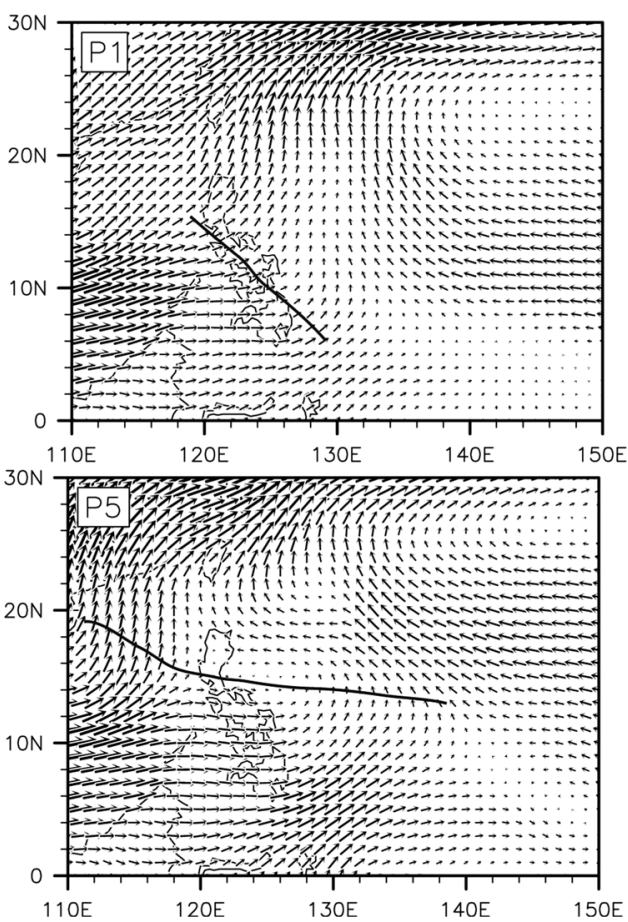

(a) early summer

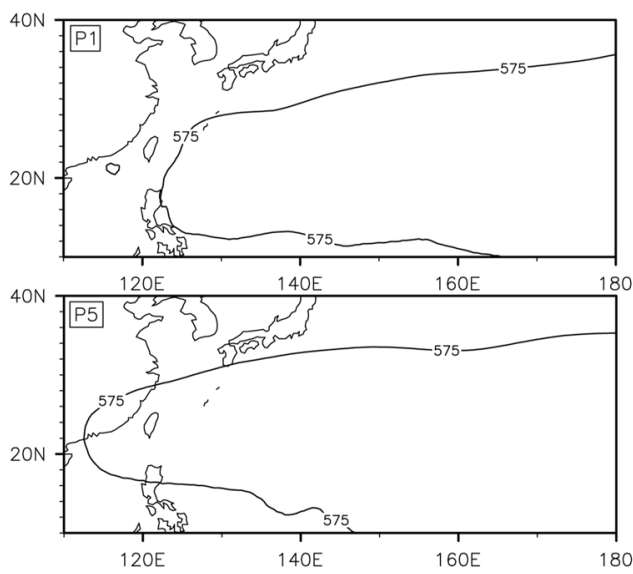

(b) late summer

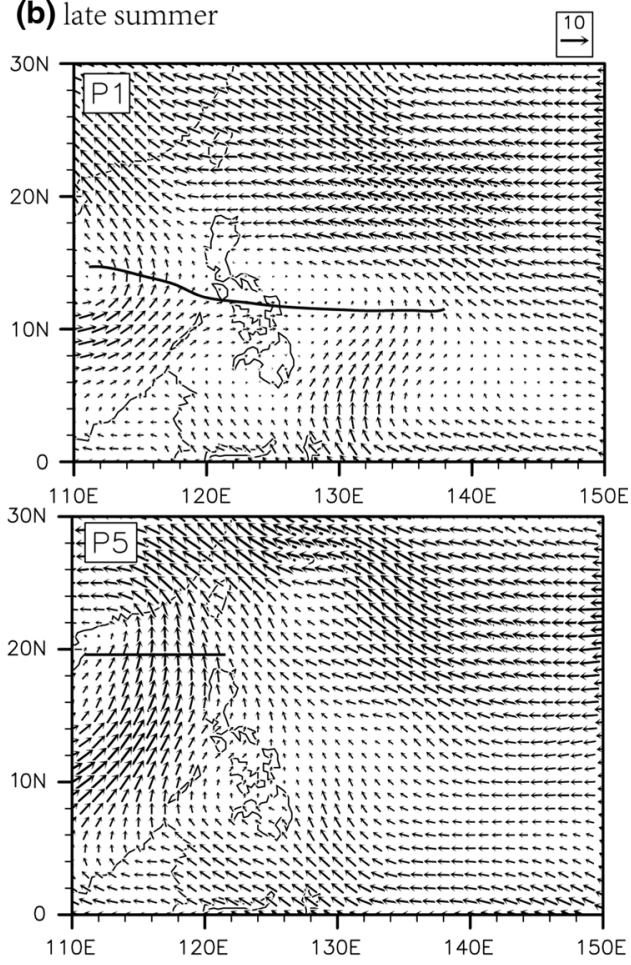

(b) late summer




Fig. 10 Composite isolines (1,225 geopotential height $10 \mathrm{~m}$ ) of $200 \mathrm{hPa}$ geopotential height respectively at phase 1 (extreme dry phase) and phase 5 (extreme wet phase) respectively in a early summer and $\mathbf{b}$ late summer

Fig. 11 Composite $500 \mathrm{hPa}$ geopotential height respectively at phase 1 (extreme dry phase) and phase 5 (extreme wet phase) respectively in a early summer and $\mathbf{b}$ late summer (a) early summer

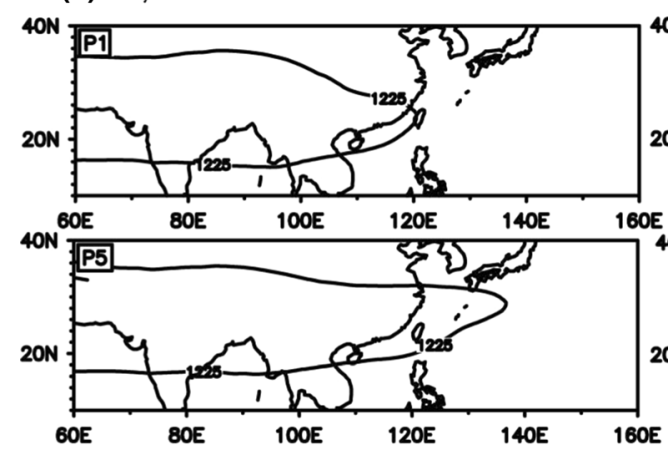

(b) late summer

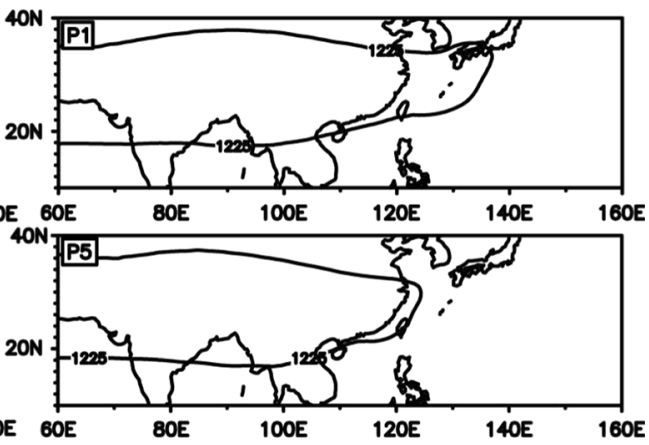

(a) Early summer

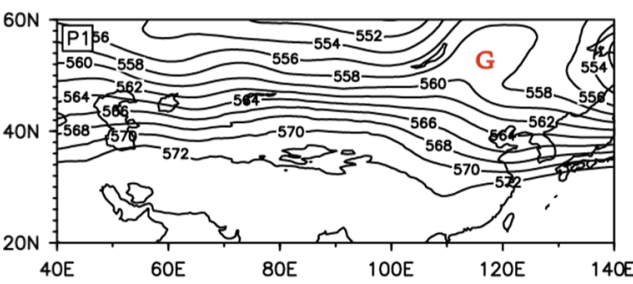

(b) Late summer

$60 \mathrm{~N}$
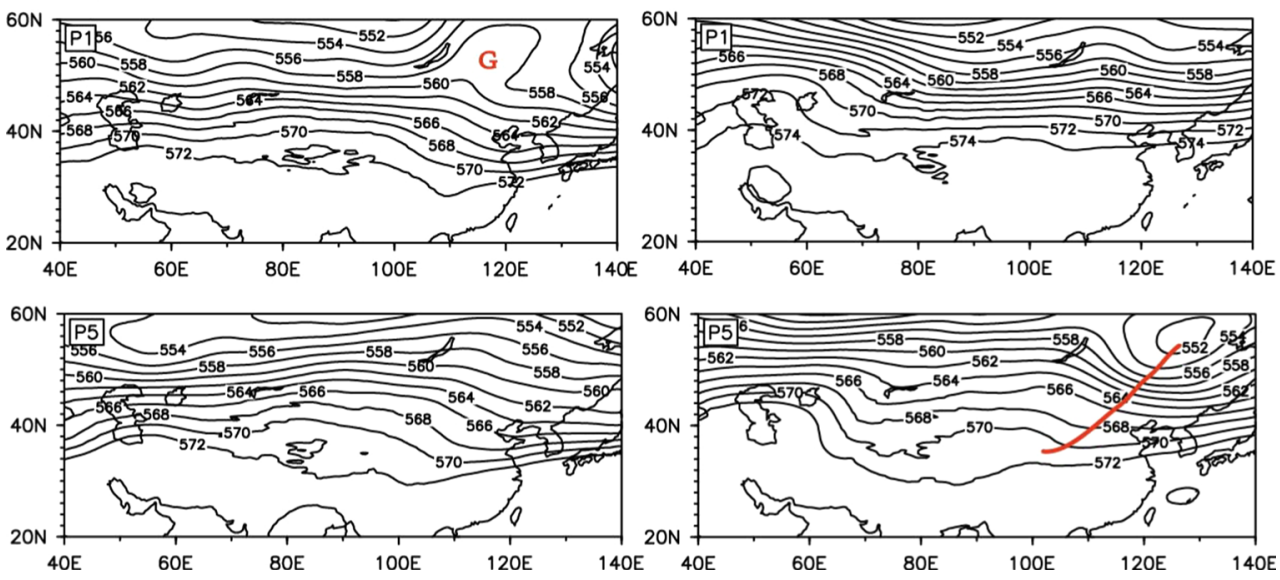

peak dry to wet phase is accompanied by the formation of the East Asian major trough, and the core region is located just downstream of the trough. Therefore, theoretically speaking, the mid-upper-level divergence over the core region can be enhanced by this huge trough (Ding 2005).

\section{Summary and discussion}

In this section, we first summarize the common and differing characteristics of QBV in early and late summer, including structure, evolution, local genesis, and associated circulation changes. Then we elaborate on how the subseasonal mean states regulate the QBV, which, we believe, is the root cause of differences in QBV behavior. Finally, we discuss the origins of QBV over EA, in an attempt to provide useful guidance for $2-3$ week predictions.

\subsection{Similarities and differences between QBV in early and late summer}

According to the previous sections, two types of schematic diagrams are proposed to summarize the features of QBV in early and late summer. Figure 12 illustrates the major anomalies at peak wet phase (phase 5) for early and late summer, while Fig. 13 compares the tracks of the major anomaly centers in early and late summer. Based on these diagrams, the common and differing characteristics of QBV in early and late summer are summarized as follows.

At peak wet phase, the major anomalies of QBV in early and late summer share a baroclinic structure (Fig. 12), with a lower-level CA and an upper-level AA over the core region of EA. However, two main differences are recognized (Fig. 12). First, the lower-level CA over the core region is elongate east-west (north-south) in early (late) summer. Accordingly, the core region is dominated by an anomalous westerly (southerly) in early (late) summer at peak wet phase. Second, the spatial distributions of major anomalies differ between the lower and upper levels. In early summer, the lower-level anomalies feature a CA over the core region and a marked AA over the northern SCSPS. In contrast, in late summer, there is again a CA over the core region, but it is accompanied by one AA over the tropical western Pacific and another over southern Japan. At peak wet phase, the most significant upper-level anomaly is a significant AA centered to the southeast of TP in early summer but an evident CA centered to the northeast of TP 


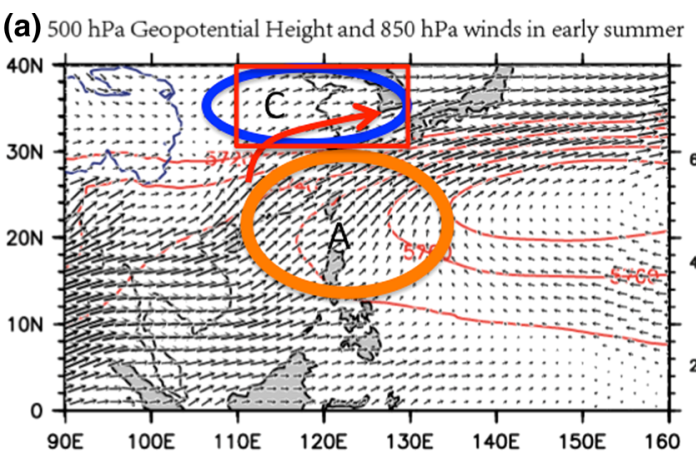

(b) $500 \mathrm{hPa}$ Geopotential Height and $850 \mathrm{hPa}$ winds in late summer

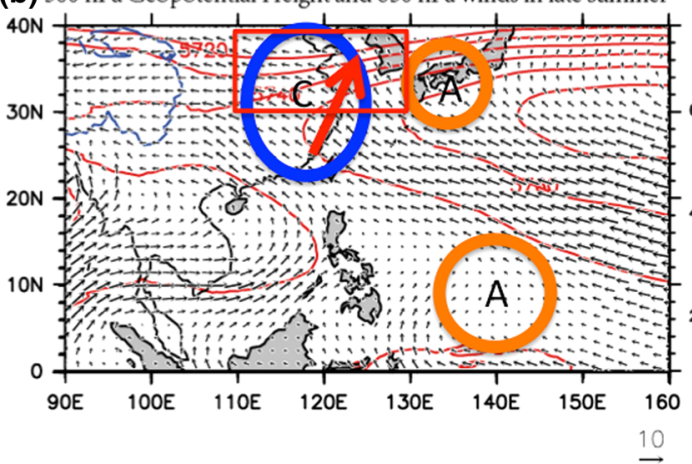

Fig. 12 a, b Spatial distributions of the major low-level anomalies at extreme wet phase in early and late summer, the background fields are the $850 \mathrm{hPa}$ winds with unit of $\mathrm{m} / \mathrm{s}$ and the $500 \mathrm{hPa}$ geopotential height with unit of $\mathrm{Pa} ; \mathbf{c}, \mathbf{d}$ Spatial distributions of the major upperlevel anomalies at extreme wet phase in early and late summer, the

in late summer. The AA in early summer is a part of a wellorganized northwest-southeast propagating wave train; the CA in late summer moves southward from south of Lake Baikal. At the same phase, the peak positive rainfall center in late summer is located north of that in early summer.

Figure 13a summarizes the different propagating tracks of the lower-level CA, which occurs over the core region at peak wet phase in both early and late summer. In early summer, the lower-level CA starts over the northern PS, and propagates approximately northwestward to southeastern China (Fig. 13a). Subsequently, the movement of the CA from southeastern China to the core region is discontinuous. The CA then moves eastward to southwest of Japan. In late summer, the lower-level CA originates from the tropical western Pacific $\left(10^{\circ} \mathrm{N}, 150^{\circ} \mathrm{E}\right)$ and takes an approximately westward path (like a tropical storm) toward the SCS (Fig. 13b). The jump of the CA from the SCS to the core region is also discontinuous. The CA then moves downstream and decays southeast of Japan.

Figure $13 \mathrm{~b}$ shows the different propagating tracks of the major upper-level anomalies, for the AA in early summer and the CA in late summer, which are the most significant signals associated with the occurrence of peak wet phase at the core region. In early summer, the AA obviously belongs to the wave train with northeast-southeast tilt, (c) $200 \mathrm{hPa}$ streamline and $200 \mathrm{hPa}$ zonal winds in early summer



(d) $200 \mathrm{hPa}$ streamline and $200 \mathrm{hPa}$ zonal winds in late summer



background fields are the $200 \mathrm{hPa}$ zonal winds (shadings are larger than $30 \mathrm{~m} / \mathrm{s}$ ) and the $200 \mathrm{hPa}$ streamline with unit of $\mathrm{m} / \mathrm{s}$. Blue cycle denotes $C A$ and orange circle denotes $A C$; and the arrow represents the dominant wind direction in low-level over the core region of $\mathrm{QBV}$

nearly along the westerly jet stream. From peak dry phase to peak wet phase, the AA moves southeastward, starting from northwest of TP at peak dry phase, via the TP at transition phases, and then reaching east China at peak wet phase. After that, the AA continuously moves eastward and decays to the southeast of Japan. In contrast, in late summer the CA originates south of Lake Baikal at dry phase, moves southward to northeastern TP at peak wet phase, then moves above TP, and finally dissipates south of TP. Different propagating tracks between the two subseasons indicate that the lower-level circulation anomalies over the northern SCS-PS and the upper-level anomalies over the northwest of TP are two important forerunners for the biweekly prediction over the core region in early summer. The lower-level anomalies over the tropical western Pacific and the upper-level anomalies over the south of Lake Baikal have meaningful leading signals for the biweekly forecast over the core region in late summer.

With respect to the local evolution over the core region, the lower-level convergence obviously precedes peak wet phase by one or two phases in early summer, but almost in phase with peak wet phase in late summer. The low-level increased moisture and ascending anomalies leads peak wet phase, which can be seen in both early and late summers. However, that the low-level positive moisture 




(b) $500 \mathrm{hPa}$ Geopotential Height and $850 \mathrm{hPa}$ winds in late summer

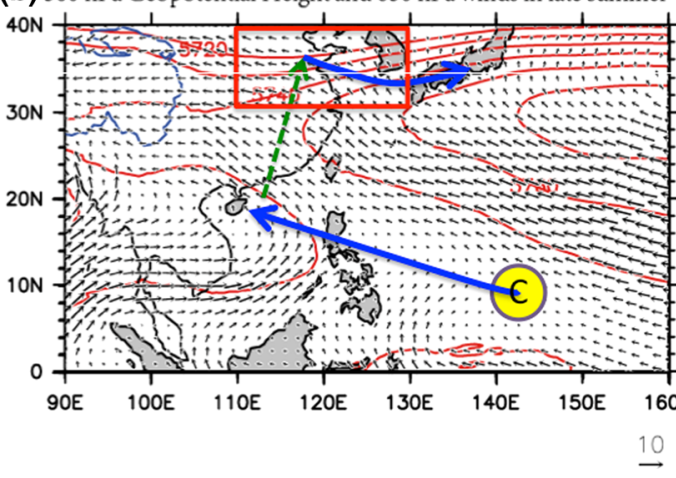

Fig. 13 Propagating tracks of $\mathbf{a}, \mathbf{b}$ the low-level CAs, $\mathbf{c}$ the upperlevel AA and $\mathbf{d}$ the upper-level CA (dominant anomalies over the core region at extreme wet phase), respectively in early and late summer.

anomaly leading the peak wet phase is more significant in early summer than in late summer. Compared with the evolution of the upper-level anomalies in early summer, the upper-level divergence appears earlier in late summer, which precedes the low-level convergence by one to two phases; meanwhile, the upper-level divergence anomalies in late summer have deeper and stronger development throughout the mid-upper levels above $400 \mathrm{hPa}$. From the perspective of biweekly rainfall prediction, the lower-level convergence and low-level increased moisture are two important precursors for the biweekly forecast in early summer; while the upper-level divergence and low-level increased moisture could be two important pilot signals in late summer.

\subsection{Effect of the background mean state}

on the behavior of QBV in early and late summer

An abrupt change of the lower-level mean state over the Asian monsoon region in mid to late July has been reported in many previous studies (e.g., Wu and Wang 2001; LinHo and Wang 2002; Ding 2004). As shown in Fig. 12, in the lower and middle troposphere, the subseasonal mean state experiences a remarkable northward movement of the subtropical high ridge (from $25^{\circ} \mathrm{N}$ to $35^{\circ} \mathrm{N}$ ) as well as an evident eastward extension of the monsoon trough from the (c) $200 \mathrm{hPa}$ streamline and $200 \mathrm{hPa}$ zonal winds in early summer

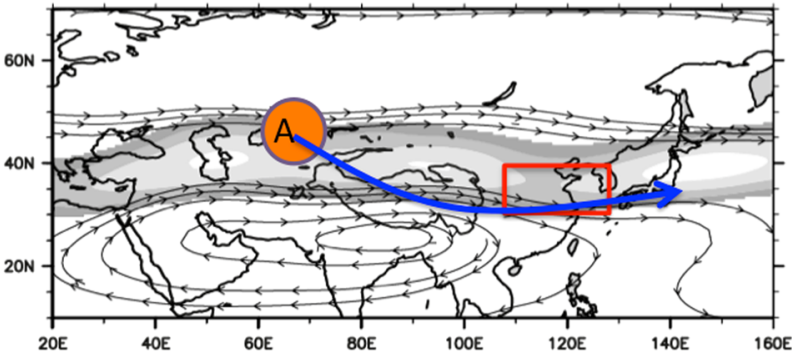

(d) $200 \mathrm{hPa}$ streamline and $200 \mathrm{hPa}$ zonal winds in late summer

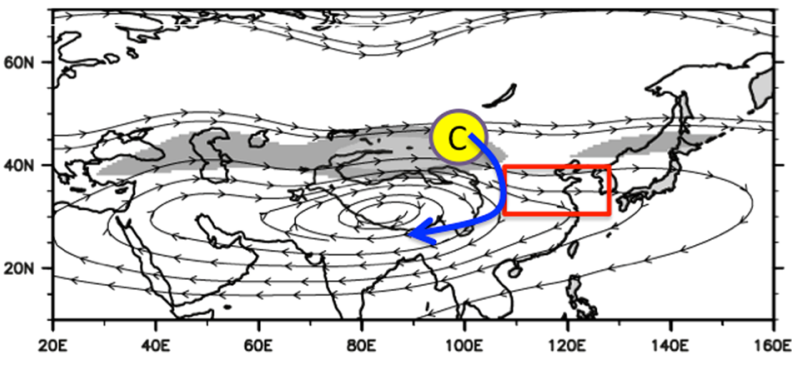

The solid circles represent the sources of the major CA or AA anomalies. The dashed green arrows in $\mathbf{a}, \mathbf{b}$ represent discontinuous transitions. The background fields are same with Fig. 12

PS to the tropical western Pacific $\left(120^{\circ} \mathrm{E}\right.$ to $\left.140^{\circ} \mathrm{E}\right)$. The monsoon trough, a region with a large moisture flux convergence (Chen and Huang 2010), is favorable for the generation of synoptic and intraseasonal perturbations in boreal summer (e.g., Harr and Elsberry 1995; Ko and Hsu 2006). From early to late summer, the source region of lower-latitude biweekly perturbation moves eastward from the northern SCS-PS to the tropical western Pacific, which is consistent with the eastward extension of the monsoon trough. The mean flow along the edge of the WNP subtropical high tends to be the steering flow related to the movement of a high-frequency perturbation (such as a tropical cyclone) (e.g., Chan and Gray 1982). Accordingly, the path of the lower-level perturbations also seems to be consistent with the climatological steering flow along the edge of the WNP subtropical high in early and late summer.

In the upper level, the westerly jet also experiences an abrupt northward movement from early to late summer (Fig. 13c, d). Meanwhile, the South Asia High (SAH) moves northward and the meridional component of the upper-level mean flow is evidently enhanced in late summer. Due to the northward march of the westerly jet and $\mathrm{SAH}$, the core region of QBV over EA is located within the westerly jet stream and is dominated by zonal westerly flow in early summer. In contrast, the core region is located south of the jet core and on the northeast of SAH, and is 
dominated by northeasterly in late summer. The upperlevel mean flow tends to be the steering flow of synoptic to intraseasonal perturbations (Fujinami and Yasunari 2004, 2009). Therefore, the propagation of quasi-biweekly perturbations is almost along the zonal westerly jet flow from west to east in early summer, but approximately follows the eastern edge of SAH from north to south in late summer. Furthermore, compared with early summer, the westerly jet becomes weakened and the jet core gets broken in the longitudes between $110^{\circ} \mathrm{E}$ and $120^{\circ} \mathrm{E}$ in late summer. Therefore, the westerly jet is not strong enough to be a waveguide so that transient wave cannot go straight eastward along the westerly stream in late summer.

The above-mentioned is the modulation of mean state on transient QBV. However, the modulation of QBV on the mean state is also significant as described in Sect. 5. From peak wet to dry phase, the monsoon trough extends eastward in early summer but retreats westward in late summer; the WNPSH extends westward in early summer but retreat eastward in late summer; and the SAH extends eastward in early summer but retreat westward in late summer. The distinctive behaviors of these synoptic circulation systems result from the superposition of the transient biweekly anomaly and the mean state.

\subsection{Discussion: sources of QBV over EA in early and late summer}

The present study further confirms the conclusion that QBVs over EA result from the tropical-extratropical interaction in both subseasons, in agreement with Yang et al. (2010). As mentioned above, the extratropical biweekly signal is mainly from the upper level, while the tropical biweekly signal evidently comes from the lower level.

We first revisit the evolution of the upper-level biweekly signals. In early summer, the northwest-southeast tilted wave train pattern is very similar to the "AT" (short for "across the TP") pattern defined in the study by Fujinami and Yasunari (2009) (hereafter FY09). The difference is that FY09 showed two contrasting upper-level patterns associated with the submonthly convection of EA summer monsoon in early summer: AT and NET (short for "northern and eastern margins of TP") patterns. We note that the years selected for NET patterns in FY09 are mostly before 1997, whereas our study uses data from after 1997. FY09 determined that the two different upper-level wave patterns are primarily caused by a mean state change at the interannual time scale. The different results between FY09 and the present study have two implications. First, the upper-level pattern associated with QBV over EA features an AT pattern during the years 1997-2007. Second, the mean state during the years 1997-2007 favors the occurrence of an AT pattern rather than the NET pattern. Consistent with previous studies (e.g., FY09), this eastwest tilted wave along the jet stream in early summer features the barotropic (not shown) Rossby wave, and is often referred to as the "Silk Road wave train," which is a dominant teleconnection pattern at both the interannual (Ding and Wang 2007) and intraseasonal time scales (Enomoto et al. 2003). The jet stream is just across the core region of EA and strong enough to be a waveguide for the Rossby wave propagation. The biweekly periodicity has been reported to be one of the dominant intraseasonal periodicities in the westerly jet (e.g., Terao 1998; Yang et al. 2010; Fukutomi et al. 2012). Therefore, we assume that the upper-level source of the biweekly variation over EA in early summer originates from the eastward propagating biweekly perturbation in the upper-level westerly jet.

In late summer, the westerly jet stream moves northward. Rather than the eastward propagation along the jet stream, the upper-level signal features a southward propagation from south of Lake Baikal (exit of the jet core and to the northeast of TP) to EA as shown in Fig. 11 of Terao (1998), because the waveguide (westerly jet) becomes weakened and the jet core suffers broken in the longitudes of subtropical EA. The southward propagation of the upper-level biweekly signal approximately along the eastern edge of TP mainly follows the upper-level steering flow on the east of SAH. The upper-level biweekly signal starts to the south of Lake Baikal, which is near the jet core exit region. Simmons et al. (1983) showed that the growing disturbances which could extract kinetic energy from the basic state are largest in the exit region of the jet core; consequently, the quasibiweekly perturbation is more easily initiated and enhanced in the jet core exits. The exit region of the upper-level jet core is the deceleration region, which favors divergent flow (Ding 2005) and facilitates the emanation of perturbation waves. Thus, the westerly jet core exit region near the south of Lake Baikal is assumed to be the source of the upperlevel biweekly signal over EA in late summer. In a previous study of biweekly variation over TP in late summer, Fujinami and Yasunari (2004) reported clockwise rotation of the biweekly anomalies along the east edge of TP.

The lower-level biweekly signals, associated with biweekly variation over EA, are from the northern SCS-PS in early summer and from the tropical western Pacific in late summer. The tropical QBV, which is well known over the tropical western Pacific (e.g., Chen and Sui 2010) and SCSPS (e.g., Yang et al. 2008), is revealed by both convection and lower-level circulation, and is characterized by westward (e.g., Annamalai and Slingo 2001) or northwestward propagation (e.g., Zhan et al. 2008). The origins of QBV have been attributed to the tropical equatorial Rossby wave (e.g., Kikuchi and Wang 2009; Chen and Sui 2010) or mixed gravity-Rossby wave (Chatterjee and Goswami 
2004). However, these previous studies paid less attention to the subseasonal differences. In this study, we find that although the source regions of biweekly lower-level signals differ between the two subseasons, they both originate along and near the tropical monsoon trough.

This leads to the question of why the tropical monsoon trough facilitates the initiation and growth of the QB perturbation. The monsoon trough has a strong cyclonic shear $(-\partial \mathrm{u} / \partial \mathrm{y}>0)$ and a prominent convergence of zonal wind $(-\partial \mathrm{u} / \partial \mathrm{x}>0)($ Chen and Sui 2010), which favors a wave accumulation process and increases wave amplitude (e.g., Webster and Chang 1988; Kuo et al. 2001). Wave accumulation produces the initial intensification of the waves (e.g., Aiyyer and Molinari 2003). In addition, the monsoon trough is characterized by easterly vertical shear (Chen and Sui 2010), which could help trap wave energy in the lower troposphere and facilitate equatorial Rossby wave growth (Xie and Wang 1996). Therefore, the monsoon trough is the major region of lower-level biweekly signal associated with QBV over EA.

Furthermore, Ko and Hsu (2006) investigated the relationship between tropical cyclones (TCs) and submonthly variations over EA during July-August, and proposed that the TCs can affect the submonthly variability of circulation over the western north Pacific during late summer. Here, we examine if there are simultaneous occurrences of TCs during the periods of 12 selected QBV events in late summer, using JTWC (Joint Typhoon Warning Center) best track data (http://www.usno.navy.mil/NOOC/nmfc-ph/ RSS/jtwc/best_tracks/). The results show that six of the events involve the westward or northwestward movement of a TC over the western Pacific (not shown). However, another six cases are not accompanied by TC activities (e.g., cases in 2002, 2006, and 2007). Therefore, TC activities can indeed be regarded as an important factor in initiating QBV over EA, but not the only factor.

When the northward/northwestward propagating lowerlevel quasi-biweekly perturbation from the lower-latitude regions (PS in early summer and tropical western Pacific in late summer) meets the eastward propagating (in early summer) or southward migrating (in late summer) upperlevel quasi-biweekly perturbation from the midlatitudes just over EA, QBV over EA is commonly generated. As addressed in Sect. 4.3, the upper-level divergence, lowerlevel convergence, increasing moisture, and ascending anomalies favor the local development of QBV over EA. Note that since the meetings of the tropical and extratropical QBV perturbations are somewhat random, QBV over EA is not considered to be as continuous as the MJO, but appears sporadically (Fig. 2).

Several questions remain to be answered. For instance, QBV genesis over EA is associated with both lower-level QBV over the northern SCS-PS/tropical western Pacific and upper-level QBV near the westerly jet. Further study is required to understand why the perturbations over these regions have biweekly periodicity and how QBV over these regions is generated. The dissipation of the biweekly anomaly in the midlatitudes and its initiation in the lower latitudes seem to have some linkages in both the lower and upper level over western Pacific (see phase 7-8 in Figs. 3, 4, $5,6)$. Whether the initiation of the tropical biweekly oscillation over western Pacific is affected by the midlatitude biweekly perturbation is still unknown. In addition, previous studies reported that that the topography of the plateau is important for the formation of the low-level vortex (convergence and CA/AA) to the east of the plateau (Yasunari and Miwa 2006; Fujinami and Yasunari 2009), which can be also seen in our study. Some previous studies found there are evident local QBV signals over TP (Zhu and Song 1984; Zhang et al. 1991; Fujinami and Yasunari 2004; Liu et al. 2007), and our study shows that the biweekly perturbation over TP comes from higher latitudes. Thus, it is worthwhile to investigate further the source and the features of QBV over TP in the two subseasons. Furthermore, QBV is one of the important ISV modes over EA, and the relationship between QBV and extreme flooding events over EA needs to be explored in the future.

Acknowledgments This study is supported by 973 Project (Grant No. 2012CB955401 and Grant No. 2012CB417203) and NSFC Grant No. 41005036 and No. 41175059. BW acknowledges support from NOAA CTB program and Global Research Laboratory (GRL) program from the Ministry of Education, Science, and Technology (MEST), Korea.

Open Access This article is distributed under the terms of the Creative Commons Attribution License which permits any use, distribution, and reproduction in any medium, provided the original author(s) and the source are credited.

\section{References}

Aiyyer AR, Molinari J (2003) Evolution of mixed Rossby-gravity waves in idealized MJO environments. J Atmos Sci 60:28372855

Annamalai H, Slingo JM (2001) Active/break cycles: diagnosis of the intraseasonal variability of the Asian summer monsoon. Clim Dyn 18:85-102

Bingham C, Godfrey MD, Tukey JW (1967) Modern techniques of power spectrum estimation. IEEE Trans 15:56-66

Chan J, Gray WM (1982) Tropical cyclone movement and surrounding flow relationship. Mon Weather Rev 110:1354-1374

Chan JC, Ai LW, Xu J (2002) Mechanisms responsible for the maintenance of the 1998 South China Sea summer monsoon. J Meteor Soc Jpn 80:1103-1113

Chatterjee P, Goswami BN (2004) Structure, genesis and scale selection of the tropical quasi-biweekly mode. Q J R Meteorol Soc 130:1171-1194

Chen TC, Chen JR (1995) An observational study of the South China Sea Monsoon during the 1979 summer: onset and life cycle. Mon Weather Rev 123:2295-2318 
Chen GH, Huang RH (2010) Interannual variation of the mixed Rossby-gravity waves and their impact on tropical cyclogenesis in the western North Pacific. J Clim 22:535-549

Chen GH, Sui C-H (2010) Characteristics and origin of quasi-biweekly oscillation over the western North Pacific during boreal summer. J Geophys Res 115:D14113. doi:10.1029/2009JD013389

Chen TC, Yen MC, Weng SP (2000) Interaction between the summer monsoons in East Asia and the South China Sea: intraseasonal monsoon modes. J Atmos Sci 57:1373-1392

Ding YH (1992) Summer monsoon rainfall in China. J Meteorol Soc Jpn 70:373-396

Ding YH (2004) Seasonal March of the East Asian summer monsoon in the East Asian Monsoon. In: Chang C-P (ed) The East Asian monsoon. World Scientific Publishing, Singapore, p 564

Ding YH (2005) Advanced synoptic meteorology. China Meteorological Press, Beijing, p 585

Ding QH, Wang B (2007) Intraseasonal teleconnection between the Summer Eurasian wave train and the Indian monsoon. J Clim 20:3751-3767

Enomoto T, Hoskins BJ, Matsuda Y (2003) The formation mechanism of the Bonin high in August. Q J R Meteorol Soc 129:157-178

Fu YF, Liu GS (2003) Precipitation characteristics in mid-latitude East Asia as observed by TRMM PR and TMI. J Meteorol Soc Jpn 81:1353-1369

Fujinami H, Yasunari T (2004) Submonthly variability of convection and circulation over and around the Tibetan Plateau during the Boreal Summer. J Meteorol Soc Jpn 82:1545-1564

Fujinami H, Yasunari T (2009) The effects of midlatitude waves over and around the Tibetan Plateau on submonthly variability of the East Asian summer monsoon. Mon Weather Rev 137:2286-2304

Fukutomi Y, Yasunari T (2002) Tropical-extratropical interaction associated with the 10-25-day oscillation over the western Pacific during the Northern summer. J Meteorol Soc Jpn 80:311-331

Fukutomi Y, Masuda K, Yasunari K (2012) Spatiotemporal structures of the intraseasonal oscillations of precipitation over northern Eurasia during summer. Int J Climatol 32:710-726

Gilman DL, Fuglister FJ, Mitchell JM (1963) On the power spectrum of "red noise". J Atmos Sci 20:182-184

Harr PA, Elsberry RL (1995) Large-scale circulation variability over the tropical Western North Pacific. Part I: spatial patterns and tropical cyclone characteristics. Mon Weather Rev 123:1225-1246

Huffman GJ, Adler RF, Morrissey MM, Crutis S, Joyce R, McGavock B, Susskind J (2001) Global precipitation at one-degree daily resolution from multi-satellite observations. J Hydrometeorol 2:36-50

Kikuchi K, Wang B (2009) Global perspective of the quasi- biweekly oscillation. J Clim 22:1340-1359

Ko KC, Hsu HH (2006) Sub-monthly circulation features associated with tropical cyclone tracks over the East Asian monsoon area during July-August season. J Meteor Soc Japan 84:871-889

Krishnamurti TN, Bhalme HN (1976) Oscillations of a monsoon system. Part I: observational aspects. J Atmos Sci 33:1937-1954

Kuo HC, Chen JH, Williams RT, Chang CP (2001) Rossby waves in zonally opposing mean flow: behavior in northwest Pacific summer monsoon. J Atmos Sci 58:1035-1050

LinHo, Wang B (2002) The time-space structure of the Asian-Pacific summer monsoon: a fast annual cycle view. J Clim 15:2001-2019

Liu XZ, Li JD (1986) Analysis of East Asian monsoon biweekly oscillation in 1982 summer. Trans Atmos Sci 2:186-190

Liu FH, Lin H (1991) Relationship between atmospheric low frequency oscillation and South Asian high variation. Plateau Meteor 10:61-69 (in Chinese)

Liu YM, Hoskins BJ, Blackburn M (2007) Impact of Tibetan orography and heating on the summer flow over Asia. J Meteorol Soc Jpn 85:1-19

Madden RA, Julian PR (1971) Detection of a 40-50 day oscillation in the zonal wind in the tropical Pacific. J Atmos Sci 28:702-708
Madden RA, Julian PR (1972) Description of global-scale circulation cells in the tropics with a 40-50 day period. J Atmos Sci 29:1109-1123

Madden RA, Julian PR (1994) Observations of the 40-50 day tropical oscillation-a review. Mon Weather Rev 122:814-837

Mao JY, Chan JCL (2005) Intraseasonal variability of the South China Sea summer monsoon. J Clim 18:2388-2402

Mao JY, Wu GX (2006) Intraseasonal variations of the Yangtze rainfall and its related atmospheric circulation features during the 1991 summer. Clim Dyn 27:815-830

Mao JY, Sun Z, Wu GX (2010) 20-50-day oscillation of summer Yangtze rainfall in response to intraseasonal variations in the subtropical high over the western North Pacific and South China Sea. Clim Dyn 34:757-761

Pan J, Bueh C, Ji LR, Shi N, Wang PX, Zhang QY, Peng JB (2008) Characteristics of Rossby wave propagation associated with the summertime persistent anomaly events of mid- and high-latitude Eurasia. Chin J Atmos Sci 32:615-628 (in Chinese)

Simmons AJ, Wallace JM, Branstator GW (1983) Barotropic wave propagation and instability, and atmospheric teleconnection patterns. J Atmos Sci 40:1363-1392

Simmons A, Uppala S, Dee D, Kobayashi S (2007) ERA-Interim: new ECMWF reanalysis products from 1989 onwards. ECMWF Newsletter 110:25-35

Sun Y, Ding YH (2008) Effects of intraseasonal oscillation on the anomalous East Asian summer monsoon during 1999. Adv Atmos Sci 25:279-296

Terao T (1998) Barotropic disturbances on intraseasonal time scales observed in the midlatitudes over the Eurasian Continent during the northern summer. J Meteorol Soc Jpn 76:419-436

Webster PJ, Chang HR (1988) Energy accumulation and emanation regions at low latitudes: impacts of a zonally varying basic state. J Atmos Sci 45:803-829

Wu R, Wang B (2001) Multi-stage onset of the summer monsoon over the western North Pacific. Clim Dyn 17:277-289

Wu BY, Zhang Y, Song YJ (1994) The longitudinal prepositions and geographical features of the 10-20 day oscillation. Scienitia Atmospheric Sinica 18:561-568

Xie X, Wang B (1996) Low-frequency equatorial waves in vertically sheared zonal flow. Part II: unstable waves. J Atmos Sci 53:3589-3605

Yang H, Li CY (2003) The relation between atmospheric intraseasonal oscillation and summer severe flood and drought in the Changjiang-Huaihe River basin. Adv Atmos Sci 20:540-553

Yang J, Wang B, Wang B (2008) Anticorrelated intensity change of the quasi-biweekly and 30-50-day oscillations over the South China Sea. Geophys Res Lett 35:L16702. doi:10.1029/2008GL034449

Yang J, Wang B, Wang B, Bao Q (2010) Biweekly and 21-30 day variabilities of the subtropical East Asian monsoon over the lower reach of Yangtze River Basin. J Clim 23:1146-1159

Yasunari T, Miwa T (2006) Convective cloud systems over the Tibetan Plateau and their impact on meso-scale disturbances in the Meiyu/Baiu frontal zone-A case study in 1998. J Meteor Soc Japan 84:783-803

Zhan RF, Sun GW, Zhao BK, Pan J, Kong CY, Wen M (2008) Quasibiweekly oscillation of the subtropical summer monsoon rainfall over East China and its possible maintaining mechanism. Plateau Meteorol 27:98-108 (in Chinese)

Zhang JJ, Sun GW, Chen BD (1991) Low frequency oscillation over Tibet Plateau. Meteor Press, p 109 (in Chinese)

Zhao GY, Liu B, Qi SJ (2000) Application of period relation between South Asian High and western Pacific Subtropical High to forecasting Shanxi rainy spell summer. Plateau Meteorol 19:172-178 (in Chinese)

Zhu BZ, Song ZS (1984) Formation of Tibet Plateau high and quasibiweekly oscillation: observation. Beijing Science Press, p 132 (in Chinese) 